\title{
Process analysis and scaling of occupational desirability: An example using information integration theory
}

\author{
MORRIS J. GRAY and IRWIN P. LEVIN \\ University of Iowa, Iowa City, Iowa 52242
}

\begin{abstract}
Information integration theory was used to study how qualitatively different job characteristics (salary, work load, and prestige) combine to influence occupational desirability in a task requiring the rating of unidentified occupations. In a second task, subjects were asked to rate overall desirability and component factors for a series of actual occupations. The data were used to generate a graphic scale of desirability for a variety of occupations and to analyze the weighting of factors affecting occupational desirability. "Prestige" was much more important in rating actual occupations than in rating unidentified occupations.
\end{abstract}

In today's tight job market, it is important to develop methods that accomplish the following two goals: (1) scaling the desirability of various occupations by relevant groups and (2) understanding how people use information about particular occupations to evaluate and choose between occupations. The present study uses information integration theory (Anderson, 1974, 1976) to pursue these goals.

As described by Mitchell and Beach (1977), recent research on occupational choice has focused on the choice process itself, and a variety of theories of human judgment and choice have been brought to bear on this problem. Studies by Sidowski and Anderson (1967) and Singh (1975) have shown that information integration theory can provide a useful tool for analyzing the process of occupational choice. Occupational evaluation and choice are seen as processes involving the evaluation of information of diverse types, the assignment of weight or importance to each dimension of information, and a rule or policy by which qualitatively different dimensions of information are combined. In the present two-part study, subjects were first asked to rate the desirability of unidentified occupations described by varying levels of salary, work load, and prestige and were then asked to rate actual occupations. The data from Part 1 were used to analyze the process by which the manipulated factors were combined to determine occupational desirability, and the data from Part 2 were used to generate a graphic scale of desirability ratings for occupations of potential interest to college students.

Requests for reprints should be sent to Irwin P. Levin, Department of Psychology, University of Iowa, Iowa City, Iowa 52242. The authors wish to express their appreciation to Norman H. Anderson and Milton E. Rosenbaum for suggesting the possibility of using information integration methodology to investigate occupational desirability, and special thanks to Thomas M. Ostrom and Martin F. Kaplan for their helpful comments on an earlier version of this manuscript.

\section{METHOD}

Forty-four students from introductory psychology classes at the University of Iowa were given the two-part self-paced task. In Part 1 , subjects were asked to rate the desirability of a series of hypothetical occupations. They were given a one-page summary of the levels of the three factors describing the hypothetical occupations: salary $(\$ 10,000-15,000 /$ year, $\$ 15,000$ $20,000 /$ year, $\$ 20,000-25,000 /$ year); workload $(30-40 \mathrm{~h} /$ week, $40-50 \mathrm{~h} /$ week, $50-60 \mathrm{~h} /$ week); and prestige (average, above average, high). They were also given a 33-page booklet where each page represented a different hypothetical occupation described by one level of each of the three factors. The occupational desirability scale was a $20-\mathrm{cm}$ line labeled "very undesirable" at one end and "very desirable" at the other end. Subjects responded by placing a slash mark somewhere along the line. Responses were recorded on a 20-point scale, with higher numbers representing higher desirability ratings. The response scale was reproduced at the bottom of each page. The first 6 pages were practice trials which were a sample taken from the range of possible combinations, and the remaining 27 represented all possible combinations of the three levels of the three factors. When a subject finished this booklet, he or she was given the first booklet of Part 2.

In Part 2 , the subjects were given a booklet that contained 27 actual occupations, in random order, that were thought to represent possible occupational choices for college graduates. Some of the occupations had been used in previous research (Dawson \& Brinker, 1971; Ryckman \& Sherman, 1974). Below the occupational titles were spaces for the subjects to rate each occupation on the three factors used in Part 1. Four alternatives were available for each factor, the three used in Part 1 and one labeled "other," where the subject could write in any other value. When subjects finished this booklet, they were given another booklet with the same occupations and were asked to rate the desirability of each on the same scale they had used in Part 1. They were not allowed to consult their ratings on the factors salary, work load, and prestige when rating occupational desirability.

\section{RESULTS}

The data from Part 1-ratings of hypothetical occupations-are summarized in Figure 1. The near parallelism of the lines in each panel suggests that an additive model 


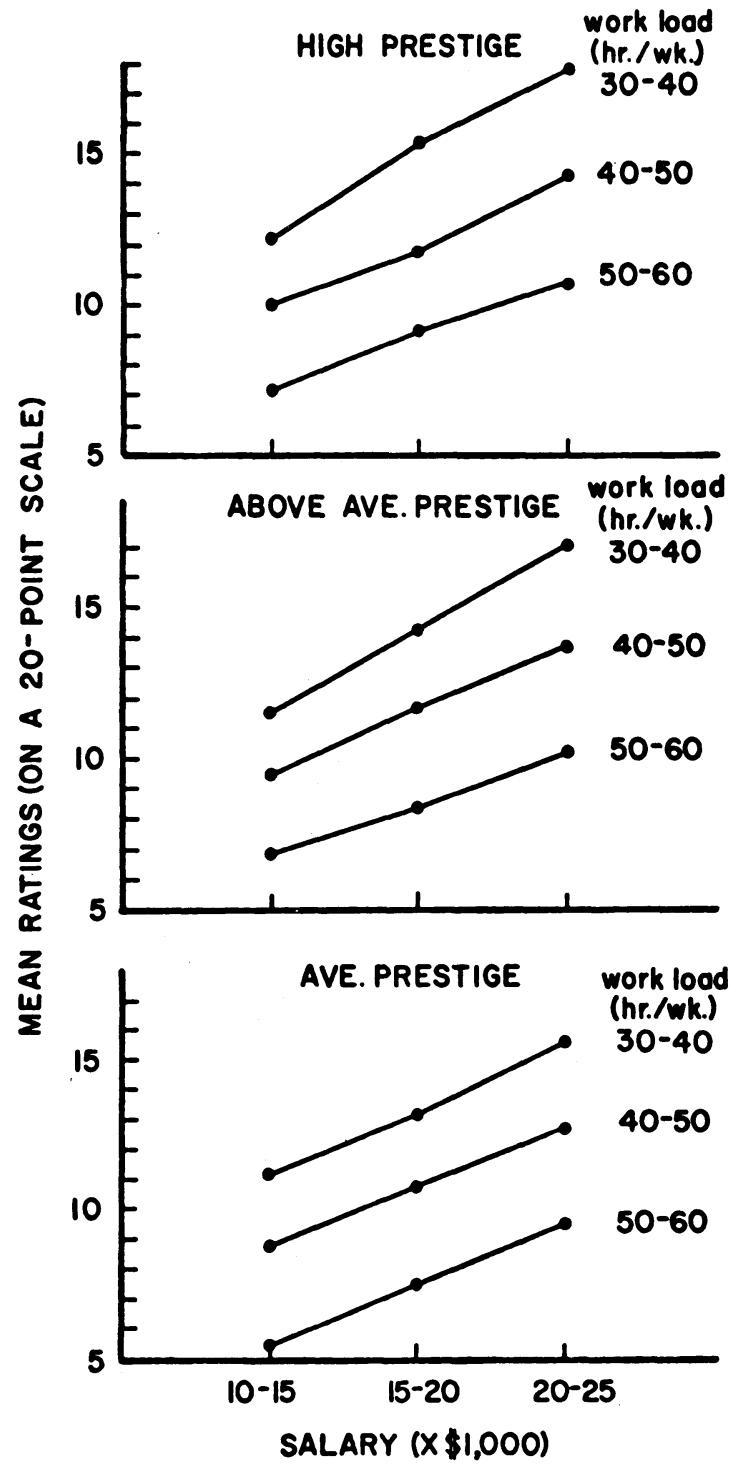

Figure 1. Mean desirability ratings for Part 1.

can adequately describe these data. However, the small departures from parallelism are systematic. The lines for different levels of work load tend to converge at low levels of salary. One parsimonious interpretation of this set of findings is that ratings are based on an averaging of the factors salary, work load, and prestige, where the less favorable levels of salary and work load have a greater weight than the more favorable levels. Similar patterns of results (i.e., averaging of stimulus factors, with the more unfavorable levels receiving greater weight) have been found in information integration studies ranging from personality impression formation (Levin, Wall, Dolezal, \& Norman, 1973) to judgments of criminal offenses (Oden \& Anderson, 1971). The systematic nature of the present findings and their commonality with previous studies tend to support the validity of the present scale of occupational desirability.
A $3^{3}$ repeated-measures analysis of variance revealed the following significant sources of variance: salary $[\mathrm{F}(2,86)=75.84]$, work load $[\mathrm{F}(2,86)=109.20]$, prestige $[F(2,86)=26.26]$, Salary by Work Load $[F(4,172)=4.59]$. Work load had a slightly larger effect than salary; prestige had a much smaller effect and did not enter into any significant interactions. The Salary by Work Load interaction represented only $.4 \%$ of the variance but, as noted above, has theoretical significance. Using methods developed elsewhere (Levin, Kim, \& Corry, 1976; Norman, 1976), the relative weights of the three factors were computed to be .37 , .50 , and .13 for salary, work load, and prestige, respectively. (Note that the weights are in fact "relative" because, in general, changing the factor levels would change the weights.)

The data for Part 2 are summarized in Table 1 and Figure 2. Prestige had a much greater effect in rating actual occupational titles than in rating unidentified occupations, while work load had a considerably reduced influence in rating actual occupational titles. Regression analysis confirmed that the relative importance of the three factors was considerably changed in the two parts of the study. Prestige had the largest effect $[F(1,23)=$ 111.77]. None of the additional (noncommon) sums of squares contributed by the other main effects and interactions reached statistical significance. This was due in large part to the intercorrelations between the three factors. These were as follows: .87 for salary and prestige, .55 for salary and work load, .37 for prestige and work load. The correlations between each factor and the desirability ratings were as follows: salary, .82; work load, .41 ; prestige, .91 . It appears that prestige ratings were heavily influenced by salary and that, in this context, desirability and prestige were nearly synonymous. An $\mathrm{R}^{2}$ of .82 indicates that the three rated factors account for a large proportion of the variance in the desirability ratings.

An inspection of the specific ratings in Table 1 reveals that salary ratings are ordered as one might expect and are relatively accurate given the alternatives that subjects were asked to use. Work-load ratings contained some surprises. Teaching-related occupationscollege professor, high-school counselor, high-school teacher-were rated as having relatively low work loads. The same is true for judge and linguist. These are occupations in which "preparation time" would be a major component, but the college students who served as subjects apparently did not view this as being as extensive as would those who are actually in these occupations. On the other hand, Iowa students rated farmer and physician as the most time-consuming occupations, and this may reflect a rural background. These results indicate that the current component rating task could be used by a counselor to identify those factors on which a job-seeker is misinformed or lacks information and could be used to indicate the relative importance of various factors for a given individual. Prestige ratings 
Table 1

Mean Ratings for Occupations in Part 2

\begin{tabular}{|c|c|c|c|c|}
\hline \multirow[b]{2}{*}{ Occupation Title } & \multicolumn{4}{|c|}{ Rating } \\
\hline & $\begin{array}{c}\text { Mean Salary } \\
(\times \$ 1,000 / \text { Year })\end{array}$ & $\begin{array}{l}\text { Mean Work Load } \\
\text { (Hours/Week) }\end{array}$ & Mean Prestige* & $\begin{array}{c}\text { Mean Desirability } \\
\text { (20-Point Scale) }\end{array}$ \\
\hline Advertising Executive & 20.45 & 45.45 & 2.25 & 12.09 \\
\hline Architect & 21.48 & 45.45 & 2.59 & 13.11 \\
\hline Artist & 14.09 & 44.55 & 1.77 & 10.11 \\
\hline Car Salesperson & 14.43 & 40.00 & .98 & 6.09 \\
\hline College Professor & 18.52 & 41.36 & 2.41 & 12.89 \\
\hline Engineer & 19.89 & 43.64 & 2.23 & 11.59 \\
\hline Farmer & 17.02 & 54.52 & 1.21 & 9.45 \\
\hline Foreign Correspondent & 18.92 & 45.80 & 2.33 & 12.25 \\
\hline High-School Counselor & 13.98 & 38.18 & 1.27 & 9.98 \\
\hline High-School Teacher & 13.66 & 40.35 & 1.23 & 9.39 \\
\hline Judge & 18.75 & 39.55 & 2.32 & 11.70 \\
\hline Junior Executive & 18.07 & 43.41 & 2.00 & 11.74 \\
\hline Lawyer & 22.73 & 47.95 & 2.86 & 14.23 \\
\hline Linguist & 15.23 & 38.18 & 1.61 & 9.79 \\
\hline Manager of Small Business & 19.43 & 48.86 & 1.57 & 10.43 \\
\hline Market Research Specialist & 18.75 & 43.64 & 2.07 & 10.77 \\
\hline Photographer & 15.23 & 42.27 & 1.39 & 11.34 \\
\hline Physician & 23.64 & 50.23 & 2.93 & 14.34 \\
\hline Plumber & 17.73 & 41.59 & 1.00 & 7.64 \\
\hline Police Officer & 13.52 & 43.18 & 1.32 & 7.00 \\
\hline Probation Officer & 13.98 & 45.45 & 1.20 & 8.68 \\
\hline Salesman (Small Store) & 10.91 & 37.50 & .82 & 5.57 \\
\hline Sales Representative & 18.52 & 46.14 & 1.86 & 11.00 \\
\hline Social Worker & 13.07 & 43.86 & 1.20 & 9.57 \\
\hline State Senator & 21.14 & 47.38 & 2.82 & 12.36 \\
\hline Stock Broker & 19.89 & 43.18 & 1.95 & 11.23 \\
\hline TV Broadcaster & 17.50 & 40.58 & 1.98 & 11.52 \\
\hline
\end{tabular}

*Prestige ratings converted to the following scale: $0=$ below average, $1=$ average, $2=$ above average, $3=$ high.

were the highest for professions such as physician, lawyer, architect, college professor, and (somewhat surprisingly) state senator. Prestige ratings were lowest for sales jobs and plumber, but were also low for farmer, social worker, high-school teacher, and high-school counselor. (There was thus a big gap in perceived prestige between high-school and college teachers.)

The occupational desirability ratings scaled in Figure 2 reveal several distinct clusters. Physician and lawyer are at the top, then architect and college professor; then most of the remaining occupations appear in array, but plumber, police officer, car salesman, and salesman (small store) are clearly at the low end of the desirability scale. The rank ordering of occupations found here is similar to that found by Dawson and Brinker (1971), but more distinct clusters were identified in the present study.

\section{DISCUSSION}

In Part 1 , subjects rated the desirability of hypothetical occupations given information on levels of salary, work load, and prestige. A graph of the results (Figure 1) showed only slight departures from parallelism, indicating that an averaging model can adequately describe the integration process if more unfavorable stimulus levels have slightly greater weight than other levels. The regularity of these data supports the assumption that the line-mark occupational desirability scale used in both Parts 1 and 2 has equal-interval properties. The clustering of occupations displayed in Figure 2 thus has substantive meaning. The rating of hypothetical occupations in Part 1 served not only to familiarize the subjects with the occupational desirability scale, but also to give meaning to the ratings of actual occupations.

Prestige ratings were highly related to overall desirability ratings for actual occupational titles (Part 2), even though the prestige factor had little influence in desirability ratings for hypothetical occupations (Part 1). A greater range for the prestige factor and a smaller range for the work load factor in Part 2 than in Part 1 could account in part for the different weightings in the two parts. However, the biggest stimulus difference between Parts 1 and 2 is the different combinations of the three factors. The independent manipulation of factors in Part 1 led to some unusual combinations (e.g., high prestige and low salary) which were not represented by any of the actual occupations in Part 2. While the inclusion of such unusual combinations could be important for understanding the process of scaling occupational desirability, it may have led subjects to place less credence on the prestige factor in Part 1 since it is the most ambiguous of the three manipulated factors. "Prestige" probably has more concrete meaning when anchored to a particular occupational title.

We suggest that simulation and controlled laboratory research can yield valuable insights into decision-making processes in a variety of applied settings. A number of such illustrations are presented in a recent volume edited by Kaplan and Schwartz (1977). However, if the particular findings of a simulation study (e.g., the parameter estimates) are to be generalizable to realistic decision-making situations, care must be taken to match the combinations of factors studied in the laboratory with the combinations present in the actual settings (see, also, Ebbesen \& Konečni, 1975). 


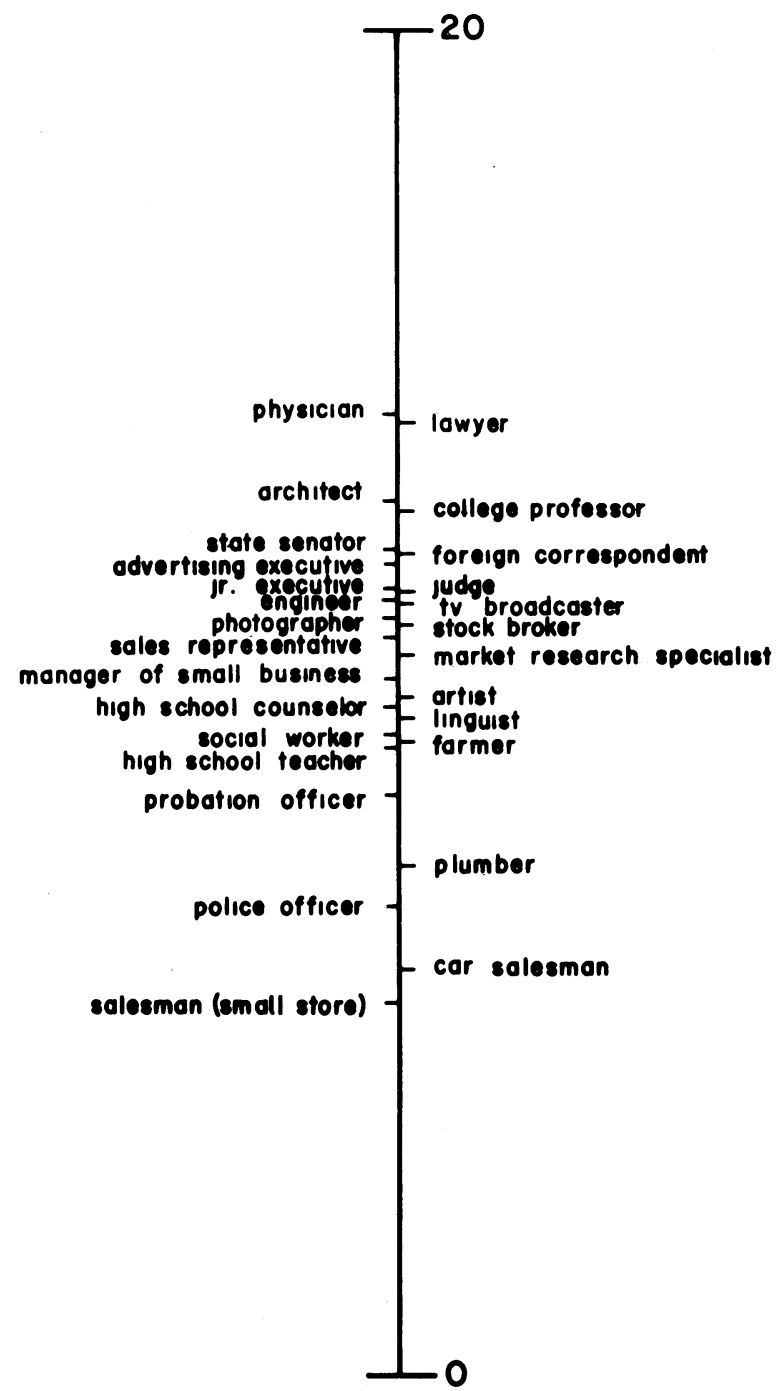

Figure 2. Mean desirability ratings for occupations used in Part 2.

Laboratory simulations and controlled research can rarely encompass as many factors as people generally use in making a complex decision. Therefore, it is important to identify and incorporate the most salient factors into an experimental design. The factors salary, work load, and prestige were meant to be illustrative but not exhaustive of the quantitative and qualitative variables affecting occupational desirability and choice. Professional counselors would be good sources for identifying other such factors. Future research using the present methods might examine how these other factors contribute to occupational desirability. Furthermore, the interaction of job charac- teristics and respondent characteristics might lead to the identification of distinct clusters of individuals who place different importance (weight) on different factors in occupational decisions.

\section{REFERENCES}

Anderson, N. H. Cross-task validation of functional measurement. Perception \& Psychophysics, 1972, 12, 389-395.

ANDERSON, N. H. Information integration theory: A brief survey. In D. H. Krantz, R. C. Atkinson, R. D. Luce, \& P. Suppes (Eds.), Contemporary developments in mathematical psychology (Vol. 2). San Francisco: Freeman, 1974.

ANDERson, N. H. How functional measurement can yield validated interval scales of mental quantities. Journal of Applied Psychology, 1976, 61, 677-692.

DAwson, W. E., \& BRINKER, R. P. Validation of ratio scales of opinions by multi-modality matching. Perception \& Psychophysics, 1971, 9, 413-417.

Ebbesen, E. B., \& Konećni, V. J. Decision making and information integration in the courts: The setting of bail. Journal of Personality and Social Psychology, 1975, 32, 805-821.

Kaplan, M. F., \& Schwartz, S. (Eds.). Human judgment and decision processes in applied settings. New York: Academic Press, 1977.

Levin, I. P., KIM, K. J., \& CorRY, F. A. Invariance of the weight parameter in information integration. Memory \& Cognition, 1976, 4, 43-47.

Levin, I. P., Wall, L. L., Dolezal, J. M., \& Norman, K. L. Differential weighting of positive and negative traits in impression formation as a function of prior exposure. Journal of Experimental Psychology, 1973, 97, 114-115.

Mitchell, T. R., \& BEACH, L. R. Expectancy theory, decision theory, and occupational preference and choice. In M. F. Kaplan \& S. Schwartz (Eds.), Human judgment and decision processes in applied settings. New York: Academic Press, 1977.

Norman, K. L. A solution for weights and scale values in functional measurement. Psychological Review, 1976 83, 80-84.

Oden, G. C., \& Anderson, N. H. Differential weighting in integration theory. Journal of Experimental Psychology, 1971, 89, 152-161.

Ryckman, R. M., \& Sherman, M. F. Locus of control and attitudes of workers and college students toward members of selected occupations. Journal of Applied Social Psychology, 1974, 4, 351-364.

SidowsKi, J. B., \& ANDERson, N. H. Judgments of cityoccupation combinations. Psychonomic Science, 1967, 7, 279-280.

SingH, R. Information integration theory applied to expected job attractiveness and satisfaction. Journal of Applied Psychology, 1975, 60, 621-623.

(Received for publication November 9, 1977.) 